\title{
Relendo Rilke shake: caçadas críticas, cidades invisíveis \& distorções
}

\author{
Gabriel José Innocentini Hayashi ${ }^{1}$ \\ não queria fazer uma leitura \\ equivocada \\ mas todas as leituras de poesia \\ são equivocadas
}

Angélica Freitas

Resumo: A proposta deste artigo é discutir alguns poemas de Angélica Freitas em seu livro de estreia, Rilke shake (2007), amarrando o texto a partir de conceitos presentes em Michel de Certeau, Juan Gabriel Vasquez, Alfonso Berardinelli e Roland Barthes. As viagens do Marco Polo de Italo Calvino nos auxiliam em nosso percurso. O papel e os pressupostos da crítica também são pensados nesse contexto.

Palavra-chave: Angélica Freitas; Rilke shake; poesia contemporânea brasileira.

Abstract: The purpose of this article is to discuss some poems of Angelica Freitas in his debut book, Rilke Shake (2007), buinding the text with concepts present in Michel de Certeau, Juan Gabriel Vasquez, Alfonso Berardinelli and Roland Barthes. Our course is aided by the travels of Marco Polo, Italo Calvino character. The role and the critical assumptions are also thought that context.

Key-words: Angélica Freitas, Rilke shake; Brazilian Contemporary Poetry.

Em seu O prazer do texto, Roland Barthes divide os textos entre os de prazer e os de fruição. Aqueles seriam os "ligados a uma prática confortável da leitura" (BARTHES, 1987, p. 21); estes, os que fazem o leitor "entrar em crise sua relação com a linguagem" (BARTHES, 1987, p. 22).

Em relação ao texto de fruição, defende Barthes, é impossível escrever sobre ele, sendo permitido apenas afirmar seu gozo. De igual para igual: apenas a escritura.

Escritura: ourobouros, ainda o privilégio: todos leitores são iguais, mas alguns os críticos - são mais iguais do que os outros. Os donos dos dados. Que muitas vezes fazem um jogo viciado.

O crítico em sua posição confortável, fruidora justamente porque "de fruição"; pobre leitor, condenado ao mero e ingênuo prazer!

Como numa balança, a morte do autor tem como contrapartida a conquista da onipotência do leitor: "a posição da leitura era assim compreendida como o espaço no

\footnotetext{
${ }^{1}$ Mestrando no Programa de Pós-Graduação em Letras da UFSCar (Universidade Federal de São Carlos); São Carlos - SP; Brasil; email: resumos@ hotmail.com. Bolsista FAPESP.

Revista Leitura v.2 no 54 - Júlio/Dez 2014 - Número temático: Leituras interartes. Relendo Rilke shake: caçadas críticas, cidades invisíveis \& distorções. Gabriel José Innocentini Hayashi. p.-193 - 206.
} 
qual o sentido plural, móbil, instável é reunido, em que o texto, seja ele qual for, adquire sua significação" (CHARTIER, 2002, p. 102). No entanto, o projeto de escritura barthesiano parece não se realizar, com exceção de seus próprios textos (que outro crítico conseguiu tal intento ${ }^{2}$ ). Este excesso é bem corrigido pelo italiano Alfonso Berardinelli (2007, p. 131): “ali onde o leitor é tudo, o autor desaparece, e a própria obra mais que aberta, pode ser definida como supérflua. Ler um texto que se autocancela não é uma aventura ascética e chocante, mas impossível ou inútil”.

Entre o prazer e a fruição, entre o conforto e a desestabilização, não haveria lugar para uma crítica capaz não de se equiparar ao que se chama de texto literário - na acepção barthesiana, a escritura - mas ao texto capaz de desestabilizar as noções do leitor referentes à leitura e literatura atravessando o texto do poeta, do prosador, do escritor?

Bem entendido: não um texto crítico equivalente ao texto literário, mas um texto que pusesse o leitor em crise, que pusesse a própria crítica em crise. (Todavia sem a necessidade de alçar o crítico ao status do escritor. A quem, senão aos críticos, interessa essa questão?)

Que deixasse o leitor na corda bamba, suspenso entre os sentidos do texto e os sentidos abertos pela crítica. Uma crítica capaz de ligar o leitor ao texto sem ser a única ponte possível, "definitiva" (as piores pontes, sempre a um passo de se tornarem obsoletas diante dos atalhos, das linhas de fugas, das desleituras, das distorções), uma crítica capaz de deslocar os sentidos, produzir sentidos novos.

Terenciano Mauro: pro captu lectoris habent sua fata libelli. Uma possível tradução: "os livros têm seu destino, segundo a recepção do leitor"3. Outra: "Por causa da inteligência de seu leitor, os livrinhos têm seu destino".

Traduções, traições, distorções.

Somente jogando às claras o crítico pode tentar elidir sua suposta superioridade, seu lugar especial, privilegiado sobre o leitor - sobre: como se estivesse acima, uma entidade especial pairando acima do leitor e do texto, capaz de, em sua visão distanciada

\footnotetext{
${ }^{2}$ Leyla Perrone-Moisés, crítica barthesiana, parece derrapar ao elogiar a escritura de Barthes. Depois de mostrar um texto do teórico francês sobre o uso do palito na cultura japonesa, Perrone-Moisés (1983, p. 58, grifos nossos) faz o seguinte comentário: "O mundo - no caso, a prática alimentar japonesa - não é expresso pelo texto de Barthes; é acrescido do texto de Barthes, substituído por ele num gozo verbal que só a escritura barthesiana - essa dosagem única de sensualidade, inteligência, humor, crítica, fantasia pôde criar e pode recriar em outros, não pelo que diz, mas por seu jeito de dizer". Ora, um mundo não pode ser substituído por um texto. Se assim fosse, seria preciso afirmar Mallarmé, para quem tudo existe no mundo para acabar em livro.

${ }_{3}^{3}$ agradeço a meu tio-avô, Mário Innocentini, que me recordou a sentença latina.
}

Revista Leitura v.2 no 54 - Júlio/Dez 2014 - Número temático: Leituras interartes. Relendo Rilke shake: caçadas críticas, cidades invisíveis \& distorções. Gabriel José Innocentini Hayashi. p.-193 - 206. 
e panorâmica, dar uma palavra imparcial, dizer algo mais justo por causa de sua posição privilegiada.

Sobre: a preposição deve deslizar, como um desvio.

Uma erótica da crítica, para dizer com (apesar de) Barthes: escrevendo nas fendas, escrevendo entre, escrevendo na insustentável leveza da crise.

Um desejo impossível ${ }^{4}$, por isso, capaz de perseguição. Como Johnny Carter, o personagem do conto de Cortázar, à beira da morte, pedindo a seu biógrafo (parodiando Dylan Thomas): “Oh, faz-me uma máscara” (CORTÁZAR, 2012, p. 94).

Visto, então, a máscara.

O escandaloso Rilke shake. Como reconstituir ao leitor o panorama no qual apareceu o livro de estreia de Angélica Freitas? Poemas postados em um blog que depois assumiram a forma de livro: o prestígio de uma casa editorial, de entrada em um sistema literário (sic) (a ficção, o desejo de um sistema literário: obras, escritores, leitores - o tripé de Antonio Candido constituindo um conjunto organizado de atores capazes de movimentar, de pôr em causa, a literatura nacional - há tal coisa hoje no Brasil?). O escândalo Angélica Freitas: a proposta de um "desmarllamento", de "vamos nos livrar de ezra pound?” (assim, em minúsculas). O som ruidoso do paideuma concreto vindo abaixo; com que ouvidos captar a vibração da queda?

Uma narrativa possível (DOMENECK, 2006, 2008) circunscrita ao brevíssimo espaço disponível neste artigo: a de parâmetros engessados, vinculados ao Modernismo brasileiro, considerado por muitos críticos ainda o auge da literatura brasileira; a dos parâmetros cabralinos, de concisão, objetividade, secura, racionalidade; de separação entre vida e arte (uma história que agora parece antiga: a proposta cerebral dos poetas concretos - cf. WILLER, 2013, p. 10-17).

Contra isso: Rilke shake. A poção antropofágica fazendo valer seus anticorpos: "um rilke shake", "um toasted blake" - e uma dança "que nem dervixe" (FREITAS, 2007, p. 39).

Eis o escândalo, logo na primeira página de Rilke shake: "shakespeare é muito bom / mas e beterrabas, chicória e agrião?” (FREITAS, 2007, p 7).

Zirma, uma das cidades invisíveis de Italo Calvino. Zirma, a cidade redundante: "repete-se para fixar alguma imagem na mente" (CALVINO, 1990 p. 23). Duplo

\footnotetext{
${ }^{4}$ Juan Gabriel Vasquez (2009, p. 12) citando Proust: "Sentimos muy bien que nuestra sabiduría comienza donde termina la del autor, y quisiéramos que nos diera respuestas, cuando todo lo que puede hacer es darnos deseos".
}

Revista Leitura v.2 no 54 - Júlio/Dez 2014 - Número temático: Leituras interartes. Relendo Rilke shake: caçadas críticas, cidades invisíveis \& distorções. Gabriel José Innocentini Hayashi. p.-193 - 206. 
movimento: a cidade e a memória se constroem juntas. Esta "repete os símbolos para que a cidade comece a existir". Estamos em um período histórico no qual escritores e textos se constroem simultaneamente. A presença midiática dos escritores às vezes deixa em segundo plano a própria obra, como um apêndice. A performance é importante; não a ponto da imagem do escritor nublar seu texto. Perigo do qual nem mesmo o atual curador da Festa Literária de Paraty parece imune ${ }^{5}$.

O leitor entra ou não no jogo. Se não entrar, a aventura se encerra. E se entrar? Então o leitor está disposto ao risco, à instabilidade da leitura, à fragilidade do corpo a corpo com o texto, marcação cerrada em todos os lugares do campo: chame de prazer, chame de fruição - o jogo começou: "mas come, come tudo que puderes, / e esquece este papo, / e me enfia os talheres" (FREITAS, 2007, p. 7).

Vladimir Nabokov parafraseado por Juan Gabriel Vasquez ${ }^{6}(2009$, p. 85) em seu El arte de la distorción:

\begin{abstract}
Aceptemos que es verdade lo que decía Nabokov: que no es posible leer un libro, sólo reelerlo, pues em la primera lectura nuestra mente está demasiado ocupada en el proceso dificilísimo de pasar los ojos sobre el papel y al hacerlo construir imágenes, cronologías, personajes; en la segunda lectura, ya conocemos todo eso y podemos fijarnos en los placeres menos evidentes de la sonoridad y la retórica y las resonancias estructurales, de ese jueguo de pequeñas satisfacciones auditivas y geométricas que es el texto de un buen estilista.
\end{abstract}

Os setores da crítica com alma de burocratas: isso é arte, isso não é arte, isso não é poesia etc (a este respeito, cf ROBIN, 1995 ${ }^{7}$ ). A necessidade do carimbo confirmando, mais do que a qualidade do que está em questão, o próprio valor e a autoridade de quem maneja o carimbo: eis alguma crítica ainda a grassar em nossas letras, a que não se põe em causa, que jamais questiona seus pressupostos, sempre sobre, sempre de fora (sem se incluir na crise). Situação que não é nova, até mesmo entediante para aqueles que pesquisam os períodos nos quais poetas irreverentes chocavam setores atrasados da crítica. Em 1976, Claudio Willer já fazia sua inventiva no "posfácio-manifesto" de seu Dias circulares:

\footnotetext{
${ }^{5}$ Cf. http://g1.globo.com/pop-arte/flip/2014/noticia/2014/07/escritor-hoje-em-dia-tem-algo-deperformatico-diz-o-curador-da-flip.html. Acesso em: 28 jul 2014.

${ }^{6}$ Agradeço à Olivia Maia pela indicação do escritor colombiano.

${ }^{7}$ Agradeço à Profa. Dra. Susana Souto Silva pela indicação deste texto.

Revista Leitura v.2 no 54 - Júlio/Dez 2014 - Número temático: Leituras interartes. Relendo Rilke shake: caçadas críticas, cidades invisíveis \& distorções. Gabriel José Innocentini Hayashi. p.-193 - 206.
} 
Basta, porém, aparecer qualquer coisa realmente inovadora em nosso meio [...] para que imediatamente assestem as baterias e se dediquem ao exercício do sarcasmo, à crítica acerba, categórica e destrutiva. Insistem em ter uma visão absolutamente desfocada do que se passa, exibem reações de dissonância frente ao novo, têm dificuldades séries na avaliação daquilo que fuja a cânones já estabelecidos, principalmente no que diz respeito a colocações mais claras da relação entre a atividade literária e o plano do social (WILLER, 2013, p. 63).

(Caricatura da crítica normativa em traços esfumaçados: recusa ao diálogo com outros pressupostos + reprodução de resultados analíticos = autoritarismo.)

De fato, bastante complicado para a crítica que resulta sempre em um "processo de monumentalização pouco sensata dos poetas do passado, em especial os do Modernismo" (SISCAR, 2010, p. 171), que ainda reivindica parâmetros formalistas, que ainda, cínica ou ingenuamente, se aferra a expressões como "poesia vendida ao mercado" - bastante complicado para essa crítica ter de se medir, ter de dizer algo em relação à poética anticanônica, antiautoritária, satírica e demolidora de Angélica Freitas. O leitor encontra o "bundão" de Gertrude Stein, "keats se sentindo mais pateta que poeta", "a bishop entre cajus toda inchada e jururu”. Irreverência e profanação, diversão e dessacralização: numa palavra, humor - o riso que destrona a crítica de seu altar, exterior a seu objeto de estudo. Entremos na fantasia imaginada por Angélica Freitas em entrevista:

Creio que o papel da poesia é do tamanho de um post-it na maioria das nações, e de um post-it bem pequeno no Brasil. Por quê? Faz de conta que aproximadamente $27,8 \%$ dos poetas da Ilha de Marajó são profundamente afetados pelas teorias de Jakobson (leem o cara, choram, meu deus, a vida deles finalmente faz sentido) e daí as utilizam como se fossem receita de bolo. A diferença é que quando dá errado eles querem te empurrar o bolo goela abaixo de qualquer jeito! Mangia che te fa bene! O piriri forma caráter! Mas esta é uma obra de ficção e de maneira alguma ocorre na Ilha de Marajó (FREITAS, 2014a).

Voltemos a Claudio Willer (2013, p. 101): "não é difícil encontrar críticas alegando que um texto é grande poesia por bater com a noção jacobsoniana de função poética, ou que não é boa poesia por ser linguagem-referência e não linguagemexpressão (juro que já vi isso, e na grande imprensa)". Willer escreveu isso em 1976; 
infelizmente os leitores de poesia contemporânea ainda encontram tais paradigmas em textos críticos em 2014.

"Teu sorriso é o que eles temem, medo" (Lô Borges, Beto Guedes, Fernando Brant).

Uma citação algo extensa de Alfonso Berardinelli oferece trilhas prenhes de sondagens mais ousadas:

\begin{abstract}
A literatura, em particular a contemporânea, é uma entidade móvel e fugidia. Para aferrá-la, para descrevê-la adequadamente, para ambientá-la no seu contexto, a crítica deve saber inventar uma linguagem adequada, com suas modalidades retóricas e estilísticas. Também a epistemologia tem a sua estilística. E a atividade crítica não é somente ciência e práxis institucional, é um empreendimento individual com riscos incalculáveis, que teoria alguma e método algum poderão jamais garantir ou proteger da falência e do erro. Portanto, em crítica literária, a forma ensaística não é pura e simplesmente "a bela escrita", longe disto. É a forma que deve fielmente corresponder à práxis real, é peripécia cognitiva através da qual um tipo específico de escritor, o crítico, conhece e constrói seu objeto; ou melhor, evita transformar a obra literária em pura entidade textual higienicamente objetivada e distanciada, sem se contaminar pela sua liberdade e riqueza, seja formal ou semântica (BERARDINELLI, 2011, p. 29).
\end{abstract}

Talvez essa cidade por construir pareça ainda por demais conservadora a alguns mais revolucionários. No entanto, permitiria assentar a discussão em novos e válidos paradigmas.

Uma nova epistemologia para uma nova poética? Trabalho de Um trabalho de formiguinha que construiria uma cidade digna de ser visitada pelo Marco Polo de Italo Calvino: a descrição, talvez no sentido arqueológico, das novas formas e das novas linguagens - em suma, das formas e linguagens que surgem na contemporaneidade. Estruturas e bases que se originassem dos textos, e não que fossem impostas como filiais de uma grande rede comercial sobre diferentes redes textuais (pequenas concessões ao gosto local ainda seriam apenas concessões). A teoria surgindo da prática. Lição de Barthes em S/Z, conforme explica Leyla Perrone-Moisés (1983, p. 49): "o recorte que ele vai dando ao texto, e as formas que sua leitura vai delineando constituem uma prática nova da crítica literária. Essas formas não são estruturas achadas no texto, mas inventadas em cima dele".

muitos, de sorte, de acaso, de colaboração. Tarefa impossível e imprescindível. 
O perigo? Que a realização dessa tarefa se transforme em Zobeide, "uma cidade feia, uma armadilha" (CALVINO, 1990a., p. 46).

Na cidade de Ipásia, Marco Polo recebe a lição de um filósofo: "Os símbolos formam uma língua, mas não aquela que você imagina conhecer" (CALVINO, 1990a, p. 48). Lição ainda não aprendida por críticos tumbosos, tumbados. "Não existe linguagem sem engano", reconhece Marco Polo (CALVINO, 1990a, p. 48). O viajante veneziano admitia também o papel do ouvinte em suas narrações: "Eu falo, falo - diz Marco -, mas quem me ouve retém somente as palavras que deseja. [...] Quem comanda a narração não é a voz: é o ouvido" (CALVINO, 1990a, p. 123). O que ecoa Paul Zumthor (2007): "Ora, a leitura do texto poético é escuta de uma voz. O leitor, nessa e por essa escuta, refaz em corpo e espírito o percurso traçado pela voz do poeta".

Le mot juste: mas quem ainda se preocupa flaubertianamente com "a palavra certa que faça o mundo andar", como canta Herbert Vianna? No erro, nos vãos, nos desvios, nas desleituras, na proliferação do efêmero, do múltiplo, do inacabado, da falta de respostas definitivas e de proteção - eis "a vida área":

o quanto você quer, me diga, com frio na barriga, proclamar norte onde seu nariz aponte, se livrar do que não interessa, com força, abrir a cabeça, meter pés pelas mãos, com pressa, não importa, sentar no escombro ombro a ombro com a obra, me diga me diga, com frio na barriga, quanto tempo perdido, quantos reais no bolso, quantos livros não lidos, quantos minutos de espera, quantos dentes cariados, me diga o quanto você quer isso tudo e para onde quer que envie, se você quer que embrulhe (FREITAS, 2007, p. 25)

Verso: o que retorna, o que não deixa de retornar, o que continua a dizer, o que se torce, a linha em convulsão, a dicção irritada: verso. E reverso: o que interroga, o que vai adiante, o que passa, o que atravessa, o outro lado. Nessa tensão, o leitor: nessa encruzilhada, nessa potência, nesse ir-e-vir. Construção que se faz na leitura, que exige o outro, que o solicita, que o constrói ao mesmo tempo em que o interpela: "a leitura não é um ato separado nem uma construção abstrata” (ZUMTHOR, 2007, p. 62).

Contra o conceito de que o leitor recebe tudo passivamente, mero coitado que mastiga o que já ruminado, reprodutor de discursos manipuladores. Certeau quer desassociar leitura de passividade: "ler é peregrinar por um sistema imposto" (1998, p. 264). Partindo do pressuposto de que "toda leitura modifica seu objeto", o teórico francês afirma: "um sistema de signos verbais ou icônicos é uma reserva de formas que esperam do leitor o seu sentido" (1998, p. 264, grifos nossos). E vai além. Para Certeau, o leitor "Inventa nos textos outra coisa que não aquilo que era a 'intenção' deles. 
Destaca-os de sua origem (perdida ou acessória). Combina os fragmentos e cria algo não-sabido no espaço organizado por sua capacidade de permitir uma pluralidade indefinida de significações" (1998 p. 264-5).

"Proclamar norte onde seu nariz aponte". Para onde, leitor, para onde?

O joio do trigo, o prazer da fruição - o crítico sabe como separá-los, como contá-los. Sabe? Onde a linha, em qualquer texto, um recado para um familiar, um despacho judicial, um dito popular, um verso vanguardista, que corta, para sempre, a euforia do vacilo da linguagem? Há algum texto em que o leitor esteja a salvo? A comoção, por mais ingênua, não seria uma prova de que a linguagem fez com que o leitor, na leitura, entrasse em crise? Onda de signos que oscilam (ZUMTHOR, 2007, p. 72): do latim signatura (atividade do olho), signum (percepção), speculum (objeto da percepção). Barthes, "me diga, me diga, com frio na barriga".

Segundo Jonathan Culler (2001, p. 78-79), a invocação que Barthes faz do corpo como origem do prazer possui quatro funções: a) estabelece um confronto à tradição cartesiana; b) baseia-se na proposição de que o sujeito consciente deve ser visto como produto de forças culturais e códigos sociais que operam através dele; c) permite-lhe evitar o problema do sujeito; d) a substituição de "mente" por "corpo" enfatiza a materialidade do significante como fonte de prazer.

No "poema pós-operatório" (FREITAS, 2007, p. 16) é a linguagem que se vê na mesa de operações. Por meio da lógica associativa poética e da análise etimológica, o leitor reconhece como a linguagem atravessa o corpo:

ex
em latim
fora de
daí algumas criaturas
parecem ter sido
desentranhadas
de você
você passa na rua
e as reconhece
ei, ali vai minha
oitava costela!
era minha!
e aponta pra lacuna
no lado esquerdo
(cabe uma gaita
de boca)


olha só!

O aceno a Manuel Bandeira, no uso de um vocábulo (desentranhada) tão caro ao poeta do Itinerário de Pasárgada, e à história bíblica da costela de Adão tramam a malha intertextual e irônica do poema. Mesmo o desfecho pode recordar a blague bandeiriana do tango argentino. Na falta do amante, contra o desamor: humor.

Em “[não adianta]” (FREITAS, 2007, p. 40), poema que parece criar um diálogo com o drummondiano "Procura da poesia", ressalta-se a ação ("é preciso / girar a chave"), o conhecimento ("e mais / é preciso saber / qual chave") e o toque, a experiência do contato ("ou então / esbarrar na dureza / de certos materiais // mogno pinho / cedro ou lâmina / de qualquer madeira"), com a consciência de que:

\author{
conhecer a chave \\ ou intuir para que \\ lado gira \\ tantos têm \\ tão pouca paciência
}

Consciente da linguagem, nos jogos de assonâncias e aliterações propostos, na tensão entre significado e significante, a poesia de Angélica Freitas mina as certezas do leitor. Aquela canção de Rita Lee: "Será que ela vai continuar uma tradição? Será que ela vai modificar uma geração?”.

Como afirma Juan Gabriel Vasquez (2009, p. 13): "en las horas de la lectura, recuperamos o recordamos aquellas cosas - ideas, emociones, pequeñas o grandes verdades - que son permanentes, que son parte de nuestra condición, y que la distracción nos há hecho perder de vista. Por um momento sentimos que entendemos, sentimos que nos entendemos".

Certeau (1998, p. 266) propõe pensar o texto como uma relação entre "um espaço legível (uma literalidade)" e a "efetuação da obra (uma leitura)". Roger Chartier (1994, p. 12) esclarece: o espaço legível são "os textos nas suas formas discursivas e materiais" e as circunstâncias dessa efetuação são "as leituras compreendidas como práticas concretas e como procedimentos de interpretação”. A proposição de Certeau ilumina-se na explicação de Chartier:

Um tal projeto repousa, por princípio, num duplo postulado: que a leitura não está, ainda inscrita no texto, e que não há, portanto, distância pensável entre o sentido que lhe é imposto (por seu 
autor, pelo uso, pela crítica etc.) e a interpretação que pode ser feita por seus leitores; consequentemente, um texto só existe se houver um leitor para lhe dar um significado (CHARTIER, 1994, p. 11).

Nas sábias palavras de Octavio Paz (1982): “O poema é criação original e única, mas também é participação e comunhão...Poeta e leitor são dois momentos de uma mesma realidade".

Nessa discussão, estão implicadas as noções de materialidade do texto e de seu suporte, os quais criam um limite à liberdade de leitura, limite este também circunscrito a outros aspectos tais como os "códigos e convenções que regem as práticas de uma comunidade" (CHARTIER, 1994, p. 14) de leitores.

Um exemplo seria o da antologia 26 poetas hoje, organizada por Heloisa Buarque de Holanda, que reconhece em seu prefácio: "A aproximação entre poesia e vida já observada no modo de produção das edições é, pois, tematizada liricamente". Os poetas da geração marginal, ou mimeógrafo, vendiam suas obras artesanais nas portas de cinemas e bares, realizando não somente o corpo a corpo com a vida em seus poemas como também o corpo a corpo de seus textos com os leitores. Caçadas: poetas à procura de vivências, experiências, confrontando a ordem estabelecida; poemas à procura de leitores.

Muita vez, o relativo sucesso (tiragens esgotadas, porém em um cenário no qual 1.500 exemplares são um sucesso em se tratando de poesia e um fracasso quando se considera o contingente de leitores possíveis no país ou a lista dos best-sellers, cujos campeões de vendas mensais oscilam entre 47.000 e 121.000 exemplares vendidos no ano de 2014, considerando os dados até o mês de julho ${ }^{8}$ ) incomoda críticos de pensamento tacanho: se vende é porque é ruim. Ignoram o fato de que os poemas fizeram seu caminho primeiro no blog de Angélica Freitas, ignoram a dinâmica dos blogs e das mídias sociais, dinâmica que permite ao leitor ser assaltado por poemas: um amigo (ou conhecido ou até mesmo desconhecido) posta um texto, o texto é replicado e em questão de minutos o alcance do poema extravasa qualquer número se considerado dentro da lógica antiga de exemplar vendido. Nem mesmo as métricas, tão importantes no sistema financeiro das redes virtuais, podem quantificar o real alcance de um texto disseminado pelas mídias sociais. Terenciano sabia: os textos encontram seus leitores.

\footnotetext{
8 A lista mensal está disponível no site Publish News: http://www.publishnews.com.br/telas/maisvendidos/listas/Default.aspx?tipo=mensal. Acesso em: 30 de jul. 2014. 
No caso de Rilke shake, o segundo poema do livro de estreia de Angélica Freitas já exibe a radicalidade dessa poética, mais do que as polêmicas propostas de descarte de Pound e Mallarmé. Leia-se “[entro na livraria do bobo]”:

\author{
entro na livraria do bobo. \\ não tenho dinheiro \\ e tampouco tenho talento para o crime. \\ desfilam ante meus olhos \\ títulos maravilhosos \\ moribundos de tanto estar \\ nas prateleiras. \\ roube-nos, dizem eles. \\ não aguentamos mais ficar aqui \\ na livraria do bobo. \\ quem acreditaria \\ nesta versão dos fatos? \\ ajudem-me, maragatos \\ nesta hora afanérrima \\ de uma libertadora paupérrima \\ de livros. \\ retumba meu coração. retumba \\ mais que a bateria do salgueiro. \\ treme o corpo por inteiro \\ e as mãos já suam em bicas. \\ ganho a rua, as mãos vazias \\ e os livros gritam: maricas \\ (FREITAS, 2007, p.8)
}

O leitor diante do espelho: caça. No outro poema: "quantos livros não lidos". Barthes (2012, p. 35): “a liberdade de leitura, qualquer que seja o preço a pagar, é também a liberdade de não ler"9. Mais do que a limpeza de terreno em relação às poéticas canônicas de Pound e Mallarmé, aqui o humor se volta para o próprio sujeito lírico do poema: alvo de humilhação e zombaria, reforçadas pela rima toante dos três últimos versos, cujo “i” agudo o encerra numa situação ridícula. Pode-se pensar também no conceito de leveza, tal como estabelecido por Calvino (1990b) em suas Seis propostas para o próximo milênio. "Mão leve" é aquele capaz de roubar de modo

\footnotetext{
${ }^{9}$ Por sinal, "O direito de não ler" é arrolado como o primeiro dos direitos do leitor no decálogo elaborado por Daniel Pennac (2008). Os outros são: 2. O direito de pular páginas; 3. O direito de não terminar um livro; 4. O direito de reler; 5. O direito de ler qualquer coisa; 6. O direito ao bovarismo (doença sexualmente transmissível); 7. O direito de ler em qualquer lugar; 8. O direito de ler uma frase aqui e outra ali; 9 . O direito de ler em voz alta; 10 . O direito de se calar.
}

Revista Leitura v.2 no 54 - Júlio/Dez 2014 - Número temático: Leituras interartes. Relendo Rilke shake: caçadas críticas, cidades invisíveis \& distorções. Gabriel José 
eficaz, sem ser pego. A leveza, então, é subvertida, negativada: ao peso da biblioteca, ao peso do roubo, contrapõem-se "as mãos vazias".

Contra a erudição calcificada, um poema antioxidante. Daí o gosto cítrico na boca de alguns leitores - aqueles ainda detentores das chaves críticas capazes de abrir qualquer poema, desde que este tenha a fechadura adequada para aquelas.

Como numa caixa chinesa ou numa boneca russa, os poemas vão se desdobrando dentro do poema "treze de outubro", misturando fantasia, desejo, passado, memória e presente:

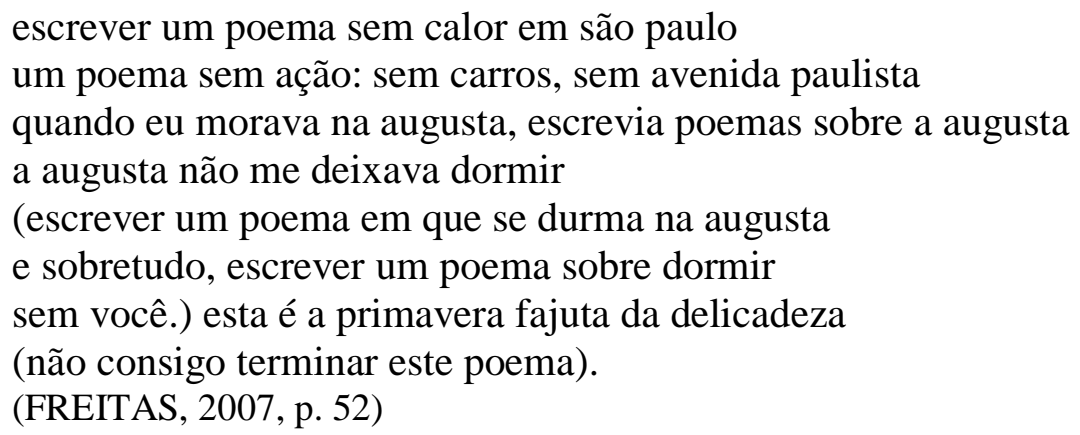

"Treze de outubro": o desejo de escrever (e de uma metrópole vazia) entrelaçado (e reforçando) à falta do ser amado; um poema que desafia o leitor ao propor o inacabado, o processo, o provisório, a incompletude da linguagem (que se reconhece "fajuta") e da experiência. O leitor é convidado a habitar os intervalos, a se mover por esse estado de suspensão: “o leitor ideal está sempre em perigo" (MANGUEL, 2009, p. 37). Segundo Juan Gabriel Vasquez (2009, p. 9), na literatura, às vezes o que é mais importante está "en uma zona imprecisa del conocimiento humano". Como afirma Roland Barthes:

talvez seja essa uma definição possível da "boa" literatura, a obra nunca é completamente insignificante (misteriosa ou "inspirada") nem jamais completamente clara; ela é, se se quiser, sentido suspenso: ela se oferece com efeito ao leitor como um sistema significante declarado, mas se furta a ele como objeto significado. Essa espécie de decepção, de desapreensão do sentido explica por um lado que a obra literária tenha tanta força para fazer perguntas ao mundo (abalando os sentidos assegurados, que as crenças, as ideologias e o senso comum parecem guardar em seu poder), sem entretanto nunca a elas responder (não há grande obra que seja "dogmática"); e, por outro lado, que ela se ofereça a um deciframento infinito, já que 
não há nenhuma razão para que se cesse um dia de falar de Racine ou de Shakespeare (BARTHES, 2007, p.161)

Talvez o escândalo provocado pelos poemas de Rilke shake venha da força com que satirizou o contexto à época. Em entrevista a Mariane Tavares, Freitas (2014b) confessou: "o Rilke escrevi para me divertir (e para divertir meia dúzia de pessoas que eu conhecia)”. Henri Bergson já dizia: “O nosso riso é sempre um riso de grupo” (1987, p. 13). Se o riso necessita da cumplicidade, o humor vem de quem tem acesso aos códigos presentes nesse grupo. Aos de fora, resta o escândalo e a indignação. É claro que, uma vez publicado, o livro ultrapassa essa esfera íntima, solicitando do leitor um conhecimento das particularidades do contexto contemporâneo para poder ser compreendido para além de leituras baseadas em parâmetros modernistas ou reféns de pontos de vista aferrados a definições rígidas do que é (ou deveria ser) a poesia.

Mais uma vez, Juan Gabriel Vasquez (2009, p. 86): "la mejor critica de novedades pone al lector em condiciones de leer um livro casi como si ló estuviera releyendo. Es decir, la mejor crítica de novedades hace sonar la alarma acerca de esos aspectos del libro que son de interes o de importancia y que el lector corre el risco de perderse".

Estes são os dois versos finais de Rilke shake: "saí num pulo / só fui rir no elevador".

\section{Referências}

BARTHES, R. O prazer do texto. São Paulo: Perspectiva, 1987.

BARTHES, R. Crítica e verdade. São Paulo: Perspectiva, 2007.

BARTHES, R. O rumor da língua. São Paulo: Martins Fontes, 2012.

BERARDINELLI, A. A forma do ensaio e suas dimensões. Remate de Males, v.31, n.12, 2011.

BERARDINELLI, A. Da poesia à prosa. São Paulo: Cosac Naify, 2007.

BERGSON, H. O riso: ensaio sobre a significação do cômico. Rio de Janeiro:

Guanabara, 1987.

CALVINO, I. Cidades invisíveis. São Paulo: Companhia das Letras, 1990a.

CALVINO, I. Seis propostas para o próximo milênio. São Paulo: Companhia das

Letras, 1990b.

CERTEAU, M. de. A invenção do cotidiano. Petrópolis: Vozes, 1998.

CHARTIER, R. A ordem dos livros: leitores, autores e bibliotecas na Europa entre os séculos XIV e XVIII. Brasília: Editora Universidade de Brasília, 1994.

CHARTIER, R. Os desafios da escrita. São Paulo: Editora UNESP, 2002.

CORTÁZAR, J. O perseguidor. São Paulo: Cosac Naify, 2012. 
CULLER, J. Barthes - a very short introduction. Oxford: OUP, 2001

DOMENECK, R. Ideologia da percepção. Inimigo Rumor: Revista de Poesia, n. 18, São Paulo, Cosac Naify, 2006.

DOMENECK, R. Concretude de correnteza e densidade de redemoinho. Germina:

Revista de Literatura \& Arte, v.4, n.16, jul. 2008. Disponível em:

<http://www.germinaliteratura.com.br/2008/literatura_jul2008_ricardodomeneck.htm>.

Acesso em: 5 maio 2014.

FREITAS, A. Rilke shake. Rio de Janeiro Cosac Naify, 2007.

FREITAS, A. Por quê poesia? Uma conversa com Angélica Freitas, Eduardo Sterzi e

Tarso de Melo. 2014. Entrevista concedida a Danilo Augusto de Athayde Fraga.

Pessoa: Revista de Literatura Lusófona, abr. 2014a. Disponível em:

http://www.revistapessoa.com/2014/04/por-que-poesia/ Acesso em 5 de maio 2014.

FREITAS, A. Entrevista com Angélica Freitas. 2014b. Entrevista concedida a Mariane

Tavares. Disponível em: http://www.salagrumo.org/notas.php?notaId=193 Acesso em: maio de 2014.

MANGUEL, A. À mesa com o chapeleiro maluco: ensaios sobre corvos e escrivaninhas. São Paulo: Companhia das Letras, 2009.

PAZ, O. O arco e a lira. 2.ed. Rio de Janeiro: Nova Fronteira, 1982.

PENNAC, D. Como um romance. Porto Alegre/Rio de Janeiro: L\&PM/Rocco, 2008.

PERRONE-MOISÉS, L. Roland Barthes. São Paulo: Brasiliense, 1983.

ROBIN, R. Extensão e incerteza da noção de literatura. In: ANGENOT, Marc e outros (dir.). Teoria literária. Lisboa: Dom Quixote, 1995.

SISCAR, M. As desilusões da crítica contemporânea: In: Poesia e crise:

ensaios sobre a "crise da poesia" como topos da modernidade. Campinas: Ed.Unicamp, 2010. p.169-181.

VASQUEZ, J. G. El arte de la distorción. Bogotá: Alfaguara, 2009. Ebook.

WILLER, C. Manifestos 1964-2010. Rio de Janeiro: Beco do Azougue, 2013.

ZUMTHOR, P. Performance, recepção, leitura. São Paulo: Cosac Naify, 2007. 